\title{
Adsorption and Photodegradation of Cationic and Anionic Dyes by $\mathrm{TiO}_{2}$-Chitosan Nanocomposite
}

\author{
Imelda Fajriati ${ }^{1, *}$, Mudasir $^{2}$, and Endang Tri Wahyuni ${ }^{2}$ \\ ${ }^{1}$ Department of Chemistry, Faculty of Science and Technology, State Islamic University Sunan Kalijaga, \\ Jl. Marsda Adisucipto Yogyakarta 55281, Indonesia \\ ${ }^{2}$ Department of Chemistry, Faculty of Mathematics and Natural Sciences, Universitas Gadjah Mada, \\ Sekip Utara, Yogyakarta 55281, Indonesia
}

${ }^{*}$ Corresponding author:

tel: $+62-81331397824$

email: imelda.fajriati@uin-suka.ac.id

Received: August 24, 2018

Accepted: December 22, 2018

DOI: $10.22146 / \mathrm{ijc} .38278$

\begin{abstract}
The adsorption and photodegradation of cationic and anionic dyes by $\mathrm{TiO}_{2}{ }^{-}$ chitosan nanocomposites have been studied. This study investigated the specific surface area, pores volume, pores size of $\mathrm{TiO}_{2}$-Chitosan nanocomposite, and determination kinetics of the reaction on the adsorption and photodegradation process. The methods were carried out by mixing $\mathrm{TiO}_{2}$-nanocomposite into cationic and anionic dyes in various contact times and initial dye concentrations. The results showed that nanocomposite adsorption capacity increased with an increase in the amount of chitosan ( $\mathrm{TiO}_{2} / \mathrm{Chit}$ 0.13 ) even though the specific surface area (SBET) was reduced. The results indicated that the adsorption on nanocomposite was influenced by the amount of $-\mathrm{NH}_{2}$ and $-\mathrm{OH}$ on the chitosan surface. The maximum adsorption capacity $\left(q_{m}\right)$ and the observed reaction constant $\left(k_{O b s}\right)$ for MO were also known to be higher than $M B$, which means that the $\mathrm{TiO}_{2}$-chitosan nanocomposites could remove anionic dye more than cationic one.
\end{abstract}

Keywords: adsorption; photodegradation; cationic dye; anionic dye

\section{- INTRODUCTION}

The increasing use of dyes in many industries had become an important problem because dyes had a serious and harmful ecosystem effect on aquatic life. Dyes have been extensively used in the textile, paper, printing, carpet, plastic, food and cosmetic industries. Therefore, intensive efforts to eliminate the dye from wastewater have gained a major concern [1].

There is a wide range of treatment technologies to remove dyes from wastewater, including physical methods (filtration, sedimentation, and distillation), chemical methods (coagulation, adsorption, photodegradation, ozonation, and ion exchanges), and biological methods using microorganism to remove dyes via aerobic-anaerobic degradation. However, such processes still have significant disadvantages, such as the requirement of waste disposal sites and additional advanced treatments to reduce waste toxicity. Furthermore, the treatment of liquid waste using such methods may take a longer time, as well as high energy requirements and high cost. The microorganism was also ineffective to delocalize the wastewater since most of the dyes were synthesized in nature, which makes them difficult to be naturally degraded by microorganism [2].

$\mathrm{TiO}_{2}$ photocatalyst method has been developed for wastewater treatment, because of some advantages, of which $\mathrm{TiO}_{2}$ photocatalyst can degrade harmful organic waste, detoxify heavy metals, and at the same time, deactivate microorganism. $\mathrm{TiO}_{2}$ photocatalyst is also a non-toxic and cheap wastewater treatment, and quite stable in many conditions such as in various $\mathrm{pH}$ and temperature.

$\mathrm{TiO}_{2}$ photocatalyst performance could be improved, one of which was immobilized in supporting material. Chitosan was an excellent adsorbent, as well as was used as supporting material. Anatase $\mathrm{TiO}_{2}$ had been successfully synthesized in situ in chitosan to form $\mathrm{TiO}_{2}-$ chitosan nanocomposite. The Nanocomposite was

Imelda Fajriati et al. 
reported to have a synergy effect in removing dyes through adsorption and photodegradation process [3]. Chitosan as the supporting material had also increased the photocatalytic activity in removing dyes because the chitosan was good adsorbent. The combination of photodegradation and adsorption process had increased the effectiveness of removing dyes in wastewater [4]. Therefore, $\mathrm{TiO}_{2}$-chitosan nanocomposite could be used to remove dye wastewater through the adsorption and photodegradation process.

This research aims to study the adsorption and photodegradation process of dyes in $\mathrm{TiO}_{2}$-chitosan nanocomposite. The adsorption and the photocatalytic process of the composites were separately evaluated and reaction conditions including contact time and various concentration of dyes were systematically investigated. The differences in the adsorption properties of the composites were intensively investigated based on the analysis using Langmuir adsorption isotherm. The dyes used in this study were methylene blue as a cationic dye (basic dye) and methyl orange as an anionic dye (acidic dye). Those dyes were widely used in textile industries and potentially hazardous to the water environment.

Methylene blue (MB) is one of the positively charged basic dye (usually amine salts or ionized imines) because $\mathrm{MB}$ ionized $\mathrm{Cl}^{-}$[5], and the other hand, methyl orange (MO) is an acidic dye with negative charge (usually organic sulfonate group, $\mathrm{RSO}_{2} \mathrm{O}^{-}$) because $\mathrm{MO}$ ionized $\mathrm{Na}^{+}$in solution [6]. The molecular structure of methylene blue (MB) and methyl orange (MO) was shown in Fig. 1.

\section{- EXPERIMENTAL SECTION}

\section{Materials}

Titanium(IV) isopropoxide (TTIP) was obtained from Sigma-Aldrich. Acetic acid 99.8\% and methyl orange $\left(\mathrm{C}_{14} \mathrm{H}_{14} \mathrm{O}_{3} \mathrm{~N}_{3} \mathrm{SNa}\right)$ was obtained from Merck. Chitosan (with $87 \%$ degrees of deacetylation) was obtained from Biotech Surindo, Cirebon, Indonesia. Distilled water and deionized water were obtained from Pharmaceutical Laboratories Jakarta. All chemicals were of reagent grade.

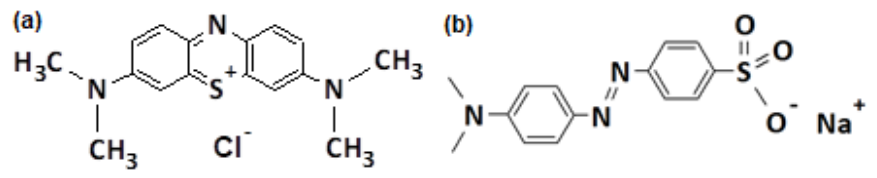

Fig 1. The molecular structure of (a) methylene blue and (b) methyl orange

\section{Instrumentation}

The chitosan solution was prepared by dissolving 3 g chitosan in $100 \mathrm{~mL}$ acetic acid 1\%, followed by vigorous stirring at room temperature for $24 \mathrm{~h}$ using magnetic stirrer at $600 \mathrm{rpm}$ (Cimarec Barnstead Thermolyne). Centrifugation was carried out using Boeco C-28 Centrifuge (Model BOE 1205-13, Boeckel \& Co, Hamburg, Germany) and oven (Thermoline Electric from Heraeus) was used for the drying process. The photocatalytic decolorization of $\mathrm{MO}$ and $\mathrm{MB}$ was conducted using a closed photoreactor equipped with magnetic stirrer and a UV lamp (40 W) operated at 290$390 \mathrm{~nm}$.

\section{Procedure}

\section{The preparation of $\mathrm{TiO}_{2}$ Sol by aging at room temperature}

The chitosan solution was prepared by dissolving $3 \mathrm{~g}$ chitosan in $100 \mathrm{~mL}$ of $1 \%$ acetic acid solution, followed by vigorous stirring at room temperature for $24 \mathrm{~h}$. Fifty milliliters of titanium(IV) isopropoxide (TTIP) was added dropwise into $500 \mathrm{~mL}$ of deionized water containing $50 \mathrm{~mL}$ of acetic acid solution, under vigorous stirring at room temperature for $24 \mathrm{~h}$. The obtained mixture was labeled as TTIP sol. Freshly prepared TTIP sol was then stored without stirring at room temperature and atmospheric pressure. It became transparent within one week.

\section{Preparation of $\mathrm{TiO}_{2}$-chitosan nanocomposites and $\mathrm{TiO}_{2}$ powders}

The TTIP sol was used to prepare $\mathrm{TiO}_{2}$-chitosan nanocomposites by sol-gel technique. Different amount of TTIP sol was added to the $3 \%(\mathrm{w} / \mathrm{v})$ of chitosan solution to reach the desired concentrations of TTIP (mol/L): 0.13, 0.33, 0.65 and 1.3, under vigorous stirring 
Table 1. The composition of chitosan and TTIP in the $\mathrm{TiO}_{2}$-chitosan nanocomposites

\begin{tabular}{lll}
\hline Chitosan $(\mathrm{g})$ & TTIP $(\mathrm{mL})$ & Nanocomposite Types \\
\hline 3.0 & 1.0 & $\mathrm{TiO}_{2} /$ Chit 0.13 \\
3.0 & 2.5 & $\mathrm{TiO}_{2} /$ Chit 0.33 \\
3.0 & 5.0 & $\mathrm{TiO}_{2} /$ Chit 0.65 \\
3.0 & 10.0 & $\mathrm{TiO}_{2} /$ Chit 1.3 \\
\hline
\end{tabular}

at room temperature for $24 \mathrm{~h}$. The resulted nanocomposites were then stored without stirring at room temperature and atmospheric pressure for two weeks (14 days). The nanocomposites were then dried at $80{ }^{\circ} \mathrm{C}$ for $60 \mathrm{~min}$ in a preheated oven. Finally, the nanocomposites were washed with distilled water until $\mathrm{pH}$ 6-7 and then dried again at $80{ }^{\circ} \mathrm{C}$ for $60 \mathrm{~min}$ in a preheated oven. The TTIP concentration of $0.13,0.33$, 0.65 and $1.3 \mathrm{~mol} / \mathrm{L}$ were used to prepare different $\mathrm{TiO}_{2-}$ chitosan nanocomposites. The samples were afterward labeled as $\mathrm{TiO}_{2} /$ Chit $0.13, \mathrm{TiO}_{2} / \mathrm{Chit} 0.33, \mathrm{TiO}_{2} /$ Chit 0.65 and $\mathrm{TiO}_{2} /$ Chit 1.3 respectively.

The composition and type of nanocomposites were given in Table 1.

\section{The adsorption process}

The Brunauer-Emmett-Teller (BET) surface areas of the nanocomposites were determined by nitrogen adsorption-desorption isotherms measured on a Quantachrome NovaWin 2 analyzer. All samples had been previously degassed before the actual measurements. The adsorption process was examined by mixing $20 \mathrm{~mL}$ of dye solution containing $\mathrm{MO}(20 \mathrm{mg} / \mathrm{L})$ and $\mathrm{MB}(10 \mathrm{mg} / \mathrm{L})$, with $0.02 \mathrm{~g}$ of each $\mathrm{TiO}_{2}$-chitosan nanocomposite $\left(\mathrm{TiO}_{2} /\right.$ Chit $0.13, \mathrm{TiO}_{2} /$ Chit $0.33, \mathrm{TiO}_{2} /$ Chit 0.65 and $\mathrm{TiO}_{2} /$ Chit 1.3) in an Erlenmeyer flask. The mixture was placed in a reactor with dark conditions. The mixture was allowed to react at different exposure time (1-8 h, with $1 \mathrm{~h}$ interval). Afterward, the mixture was centrifuged at $3000 \mathrm{rpm}$ for $5 \mathrm{~min}$. The filtrate was then measured by UV-Vis at $464 \mathrm{~nm}$ to identify the removal of dye before and after mixing with nanocomposite. The same procedure was applied to different concentrations of $\mathrm{MO}$ $(10,30,40$ and $50 \mathrm{mg} / \mathrm{L})$ and $\mathrm{MB}(5,15,20$ and $25 \mathrm{mg} / \mathrm{L})$.

\section{The photodegradation process}

The photodegradation process was conducted by mixing $0.02 \mathrm{~g}$ of each $\mathrm{TiO}_{2}$-chitosan nanocomposite $\left(\mathrm{TiO}_{2} /\right.$ Chit $0.13, \mathrm{TiO}_{2} /$ Chit $0.33, \mathrm{TiO}_{2} /$ Chit 0.65 and $\mathrm{TiO}_{2} /$ Chit 1.3) with $20 \mathrm{~mL}$ of $\mathrm{MO}(10,20,30,40$ and $50 \mathrm{mg} / \mathrm{L})$ and $\mathrm{MB}(5,10,15,20$ and $25 \mathrm{mg} / \mathrm{L})$ in an Erlenmeyer flask. The mixture was placed in the photoreactor equipped with a UV lamp (40 W) at 290$390 \mathrm{~nm}$, and it was allowed to react at different contact time (1-8 h, with $1 \mathrm{~h}$ interval). The MO and MB solution was then by UV spectrometry at $464 \mathrm{~nm}$.

\section{- RESULTS AND DISCUSSION}

The study of adsorption and photodegradation properties were conducted separately by preparing four types of nanocomposites with different ratio of $\mathrm{TiO}_{2}$ and chitosan (labeled as $\mathrm{TiO}_{2} /$ Chit $0.13, \mathrm{TiO}_{2} /$ Chit 0.33 , $\mathrm{TiO}_{2} /$ Chit 0.65 and $\mathrm{TiO}_{2} /$ Chit 1.3). Those nanocomposites were studied in several adsorption conditions, including various contact times and initial concentrations of dye.

\section{The Effect of Contact Time}

The effect of contact time to the dye adsorption and photodegradation was analyzed by reacting $20 \mathrm{mg} / \mathrm{L}$ $\mathrm{MO}$ and $10 \mathrm{mg} / \mathrm{L} \mathrm{MB}$ with $0.02 \mathrm{~g}$ of each $\mathrm{TiO}_{2}$-chitosan nanocomposite type, within various contact time. The experiment was carried out in a reactor with dark conditions (without light) to examine the adsorption of dyes on the nanocomposite surface, and in a reactor with light conditions (with UV light) to determine the photodegradation of dyes. The effect of contact time, with and without the light, is shown in Fig. 2-5.

The percentage of degraded dyes significantly increased for the first three hours, before it slowed down and became constant (Fig. 2 and 3). The slow degradation and tendency of being constant could be attributed to the depletion of dyes in solution. In the dark conditions, the removal of dyes in solution was mostly caused by adsorption on the surface of the nanocomposite. The Nanocomposites containing small amounts of $\mathrm{TiO}_{2}$ had produced higher adsorption because the free site active groups such as $\mathrm{NH}_{2}$ and $-\mathrm{OH}$ were much more on chitosan. The dye adsorption on chitosan formed coordination bonds resulted from interfacial interactions between the base sites $\left(\mathrm{NH}_{2}\right)$ 

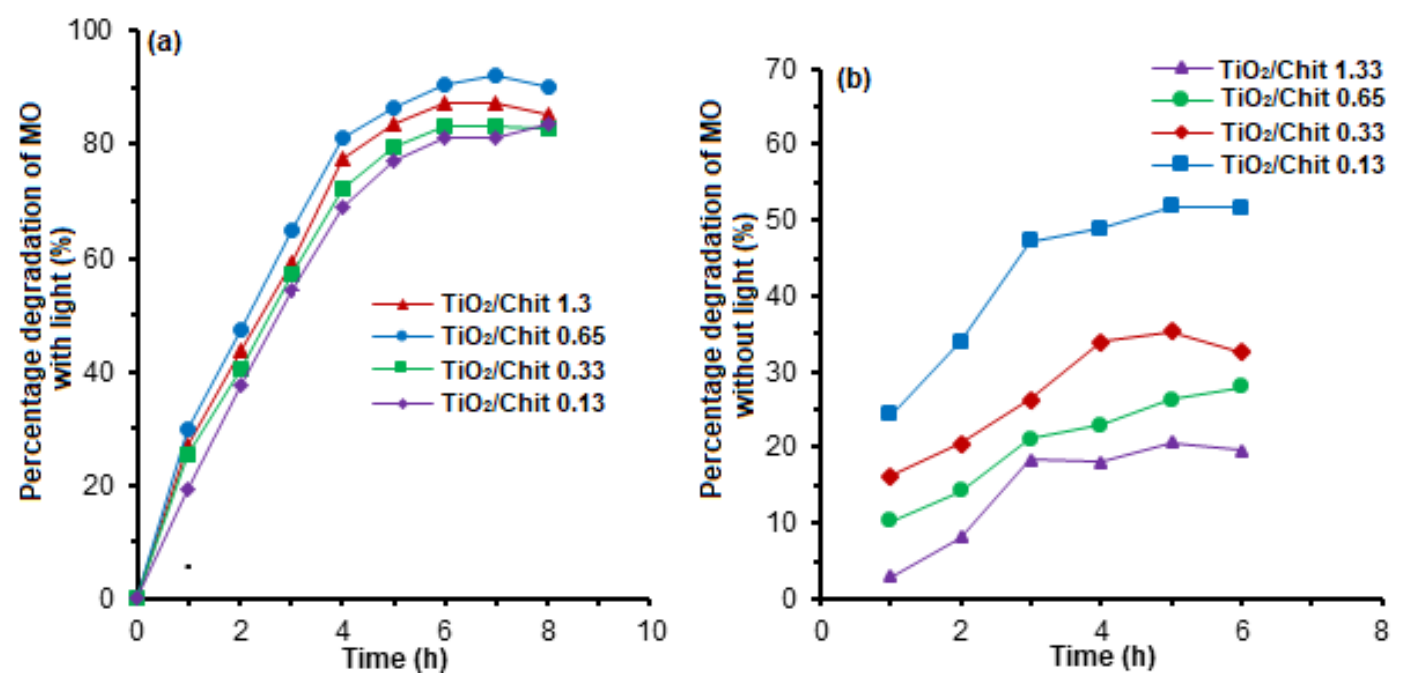

Fig 2. The effect of contact time on the adsorption and photodegradation of MO with light (a) and without light (b)
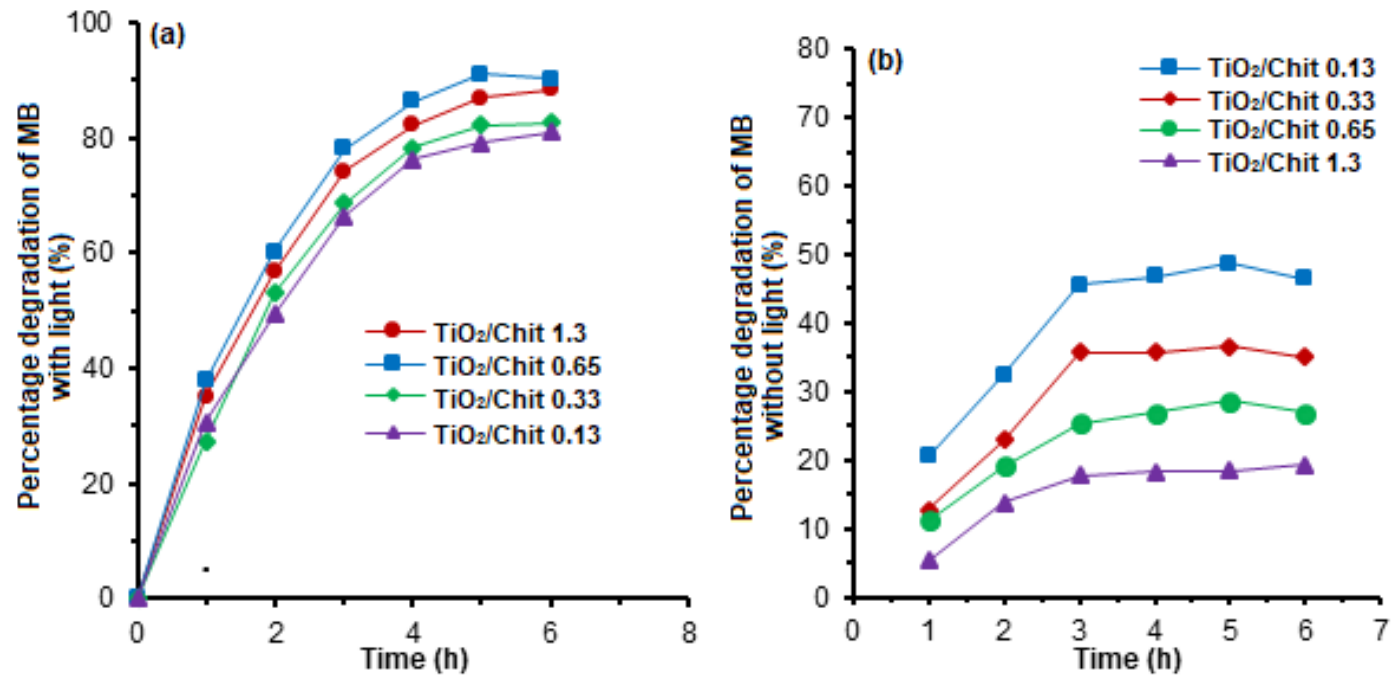

Fig 3. The effect of contact time on the adsorption and photodegradation of MB with light (a) and without light (b)

available on chitosan and Lewis acid sites from titanium [7]. Therefore, increasing the amount of $\mathrm{TiO}_{2}$ in nanocomposites had resulted in fewer sites of $-\mathrm{NH}_{2}$ and $\mathrm{OH}$ in chitosan. Thus, the nanocomposite $\mathrm{TiO}_{2} /$ Chit 0.13 had the highest adsorption activity and the lowest photodegradation process. The dye adsorption on $-\mathrm{NH}_{2}$ and $-\mathrm{OH}$ groups in chitosan was higher than in $\mathrm{TiO}_{2}$.

\section{The Effect of the Initial Concentrations of Dye Solution}

The initial concentration of dye solution had influenced the adsorption and photodegradation as it involved the amount of reacted pollutant (Fig. 3 and 4).
The increasing concentrations enhanced the amount of adsorbed and degraded dyes until the increase rate became insignificant or constant. High adsorption on the photocatalyst surface could enhance the photodegradation process. However, if the increase in dye concentration was too high, the nanocomposite would be saturated because the adsorption capacity was exceeded [8]. In addition, if the dye concentration is too high, the photodegradation could be reduced because abundant dyes could block the penetration of light into $\mathrm{TiO}_{2}$. Therefore, the adsorption and photodegradation process was not significantly influenced by the dyes which had a too high concentration. 

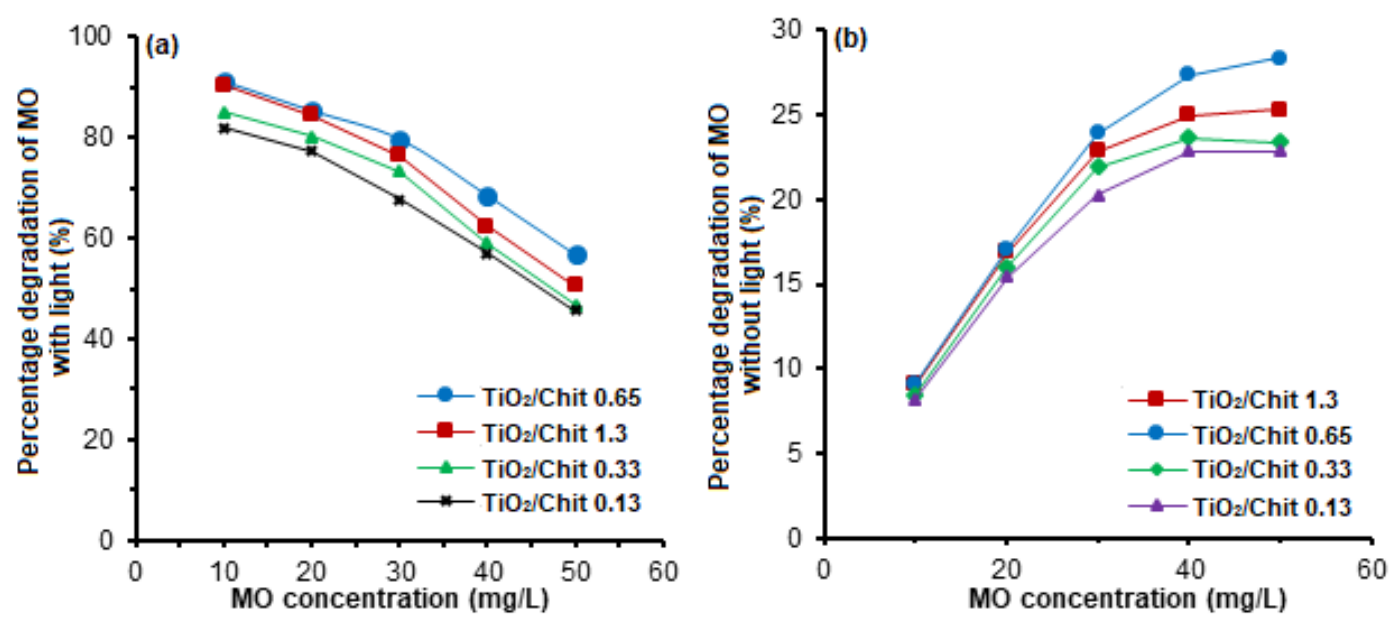

Fig 4. The effect of initial dye concentration on the adsorption and photodegradation of MO with light (a) and without light (b)
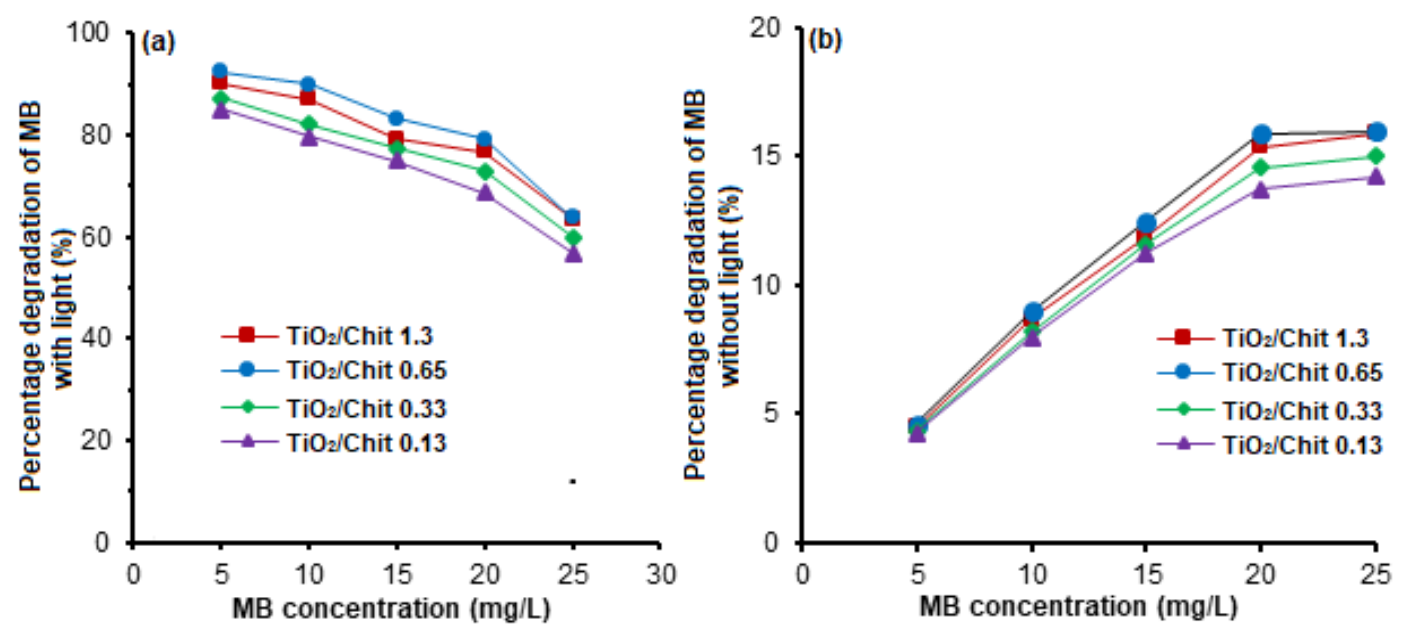

Fig 5. The effect of initial dye concentration on the adsorption and photodegradation of MB with light (a) and without light (b)

\section{The Adsorption of Cationic and Anionic Dyes by $\mathrm{TiO}_{2}$-Chitosan Nanocomposite}

The adsorption of cationic and anionic dyes on nanocomposite occurred when the dyes interacted directly in a particular time. The dye adsorption on nanocomposite surface was investigated under dark conditions (without light).

\section{BET analysis}

BET analysis was conducted to determine the specific surface area, which this property corresponds to the adsorption capacity of the nanocomposite. The BET analysis resulted from the four nanocomposites types with chitosan and $\mathrm{TiO}_{2}$ bulk as references, as shown in Fig. 6.

According to the Brunei-Deming-Teller (BDDT) classification, the chitosan bulk graph was found to be of a sigmoid type and BET classification of type 2, which was solid-nonporous materials. On the other hand, the $\mathrm{TiO}_{2}$ bulk followed the type 4, with the specific flow of hysteresis loop for mesoporous material that resulted in a large surface area [9].

Nevertheless, the nonporous material such as chitosan had a rather strong adsorbent-adsorbate interaction due to the presence of $-\mathrm{NH}_{2}$ and -OH active groups. Table 2 showed the characters of porous chitosan 

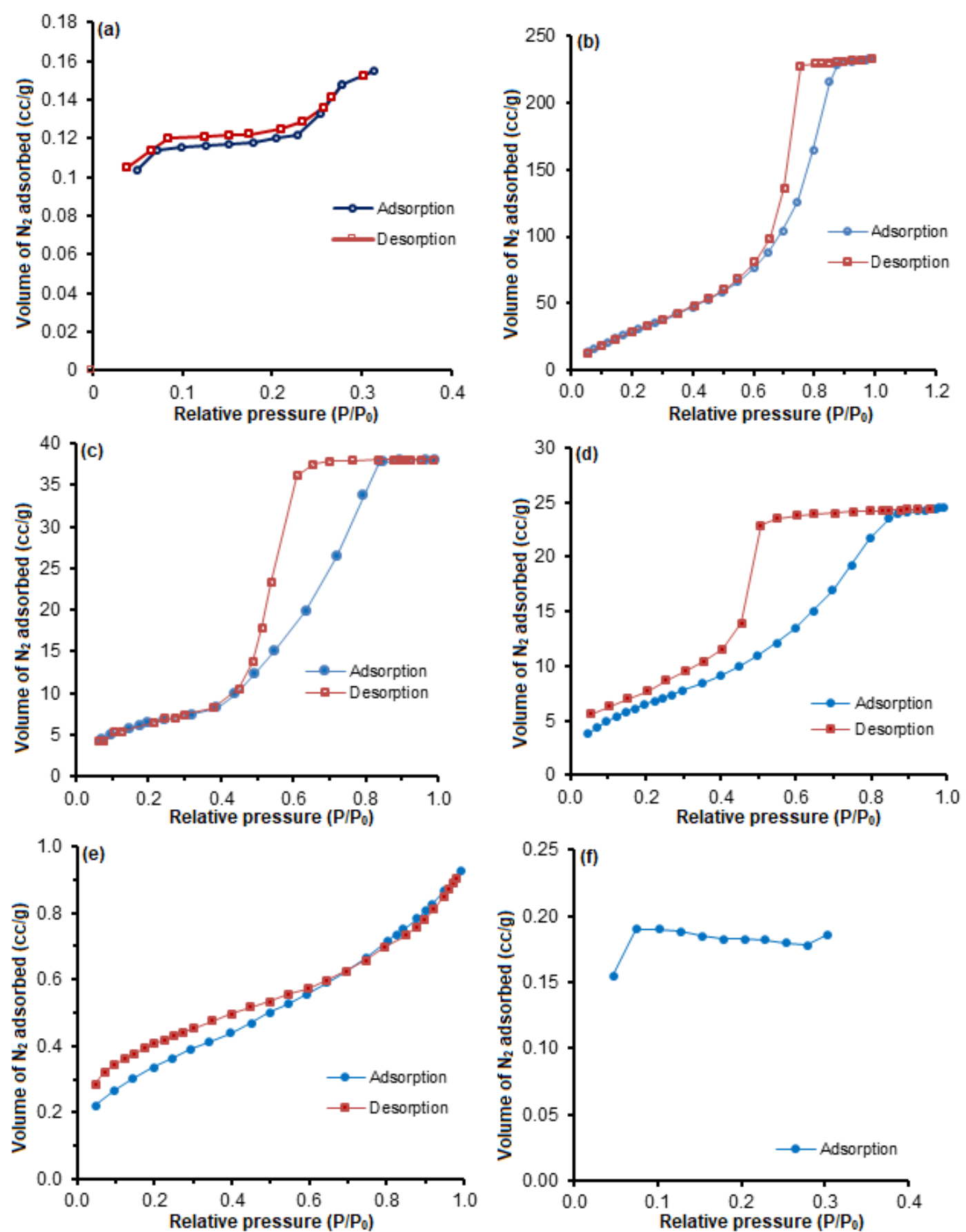

Fig 6. The $\mathrm{N}_{2}$ adsorption - desorption isothermic graph of Chitosan (a); $\mathrm{TiO}_{2}$ bulk (b); $\mathrm{TiO}_{2} / \mathrm{Chit}_{1.3}$ (c); $\mathrm{TiO}_{2} / \mathrm{Chit}$ 0.65 (d); $\mathrm{TiO}_{2} /$ Chit 0.33 (e); $\mathrm{TiO}_{2} /$ Chit $0.13 \mathrm{~mol} / \mathrm{L}(\mathrm{f})$

bulk, $\mathrm{TiO}_{2}$ bulk and types of $\mathrm{TiO}_{2}$-chitosan nanocomposite, including the specific surface area, the total pore volume and the average pore diameter, using the Brunauer-Emmet-Teller (BET) method.

The specific surface area, the total pore volume, and the pores size were increased by a higher amount of $\mathrm{TiO}_{2}$ in the nanocomposite. Conversely, the reduced number of $\mathrm{TiO}_{2}$ could decrease the specific surface area, because the pore particles of $\mathrm{TiO}_{2}$ were covered by bulk chitosan [10].

According to the classification by BDDT, the adsorption-desorption isotherm graphs of $\mathrm{TiO}_{2} /$ Chit 1.3 
Table 2. The BET analysis of $\mathrm{TiO}_{2}$-chitosan nanocomposites

\begin{tabular}{lccc}
\hline $\begin{array}{l}\text { Nanocomposite } \\
\text { type }\end{array}$ & $\begin{array}{c}\text { Specific surface area } \\
\left(\mathrm{S}_{\text {BET }}\right)\left(\mathrm{m}^{2} / \mathrm{g}\right)\end{array}$ & $\begin{array}{c}\text { Total pore volume } \\
\left(\mathrm{cm}^{3} / \mathrm{g}\right)\left(\times 10^{-2}\right)\end{array}$ & $\begin{array}{c}\text { Pore diameter } \\
(\AA)\end{array}$ \\
\hline Chitosan Bulk & 0.63 & $9.8 \times 10^{-4}$ & 15.257 \\
$\mathrm{TiO}_{2}$ Bulk & 138.31 & 39.10 & 47.02 \\
$\mathrm{TiO}_{2} /$ Chit 1.3 & 29.76 & 4.08 & 20.22 \\
$\mathrm{TiO}_{2} /$ Chit 0.65 & 25.50 & 3.79 & 18.92 \\
$\mathrm{TiO}_{2} /$ Chit 0.33 & 1.42 & 1.34 & 15.25 \\
$\mathrm{TiO}_{2} /$ Chit 0.13 & 0.54 & - & - \\
\hline
\end{tabular}

and $\mathrm{TiO}_{2} /$ Chit, 0.65 nanocomposites tended to follow type 4 with the specific flow of the hysteresis loop for mesoporous material. Meanwhile, the $\mathrm{TiO}_{2} / \mathrm{Chit} 0.33$ and $\mathrm{TiO}_{2} /$ Chit 0.13 nanocomposites appeared to follow the type 1 and type 2, which was specific to the solidnonporous material and microporous.

The $\mathrm{N}_{2}$ adsorption-desorption graph of $\mathrm{TiO}_{2} /$ Chit 0.65 and $\mathrm{TiO}_{2} /$ Chit 1.3 nanocomposites showed, that under the low condition of relative pressure $\left(\mathrm{P} / \mathrm{P}_{0}\right)$, the desorption and desorption graphs did not overlap. This unusual case could occur in metastable materials such as chitosan. These properties were indicated by the presence of interconnected pores like a tinted bottle and the random pore distribution. Therefore, the desorption process could happen through percolation mechanism, of which that enclosed the outflow of the gas phase from the pores. The confined gasses in the pores was accumulated and would be released out simultaneously under low pressure. As a result, the adsorption-desorption graph showed that more gases were desorbed than adsorbed [11].

\section{Adsorption isotherm}

Some adsorption isotherm models were studied to understand the adsorption process. One of the adsorption isotherm models is the Langmuir isotherm model. The equation for Langmuir adsorption isotherm is as follows [12-13]:

$\frac{\mathrm{C}_{\mathrm{e}}}{\mathrm{q}_{\mathrm{m}}}=\frac{\mathrm{C}_{\mathrm{e}}}{\mathrm{q}_{\mathrm{e}}}+\frac{1}{\mathrm{~K}_{\mathrm{L} .} \mathrm{q}_{\mathrm{e}}}$

$\mathrm{C}_{e}$ is the concentration of dyes ( $\mathrm{MO}$ and $\mathrm{MB}$ ) in solution $(\mathrm{mg} / \mathrm{L}), \mathrm{K}_{\mathrm{L}}$ is the Langmuir constant that associated to the adsorption energy $(\mathrm{L} / \mathrm{mg}), \mathrm{q}_{e}$ is the amount of dye absorbed per $1 \mathrm{~g}$ of catalyst $(\mathrm{mg} / \mathrm{g})$, and $\mathrm{q}_{\mathrm{m}}$ is the maximum adsorption capacity $(\mathrm{mg} / \mathrm{g})$. The adsorption isotherm graph was used to define the adsorption equilibrium time or the adsorption capacity, which was determined through various contact time, as shown in Fig. 4 and Fig. 5.

Based on the adsorption isotherm graph in Fig. 7, the maximum adsorption capacity $\left(\mathrm{q}_{\mathrm{m}}\right)$ value and the adsorption equilibrium constant $\left(\mathrm{K}_{\mathrm{L}}\right)$ of the nanocomposite to dye molecules could be calculated from the equation of line curve $\mathrm{C}_{\mathrm{e}} / \mathrm{q}_{\mathrm{m}}$ versus $\mathrm{C}_{\mathrm{e}}$ (Table 2). The Fig. 7 showed that the adsorption of dyes by nanocomposite followed the Langmuir isotherm model, suggested that each pollutant of $\mathrm{MO}$ and $\mathrm{MB}$ was specifically bound to the nanocomposite surface in monolayer and homogenous dispersion.

Table 3 pointed out that the nanocomposites had a stronger interaction with $\mathrm{MO}$ than $\mathrm{MB}$, as indicated by the higher maximum adsorption capacity $\left(\mathrm{q}_{\mathrm{m}}\right)$ and Langmuir equilibrium constant $\left(\mathrm{K}_{\mathrm{L}}\right)$ against $\mathrm{MO}$ than against $\mathrm{MB}$. This occurred because $\mathrm{MO}$ was an anionic dye that could interact electrostatically with the protonated $-\mathrm{NH}_{2}$ on the nanocomposite, while $\mathrm{MB}$ was a cationic dye that could produce repulsing force due to the same electric charge. The adsorption of negatively charged MO occurred through the electrostatic attraction to protonated $-\mathrm{NH}_{2}$ [12], while the adsorption toward the positively charged $\mathrm{MB}$ occurred due to the attraction of hydrogen bond and ion exchange with - $\mathrm{OH}$ groups [13].

Increased maximum adsorption capacity $\left(\mathrm{q}_{\mathrm{m}}\right)$ was not always linear with increasing specific surface area (SBET) (Fig. 8). Nanocomposite containing the highest amount of $\mathrm{TiO}_{2}$ had the largest SBET, while the 

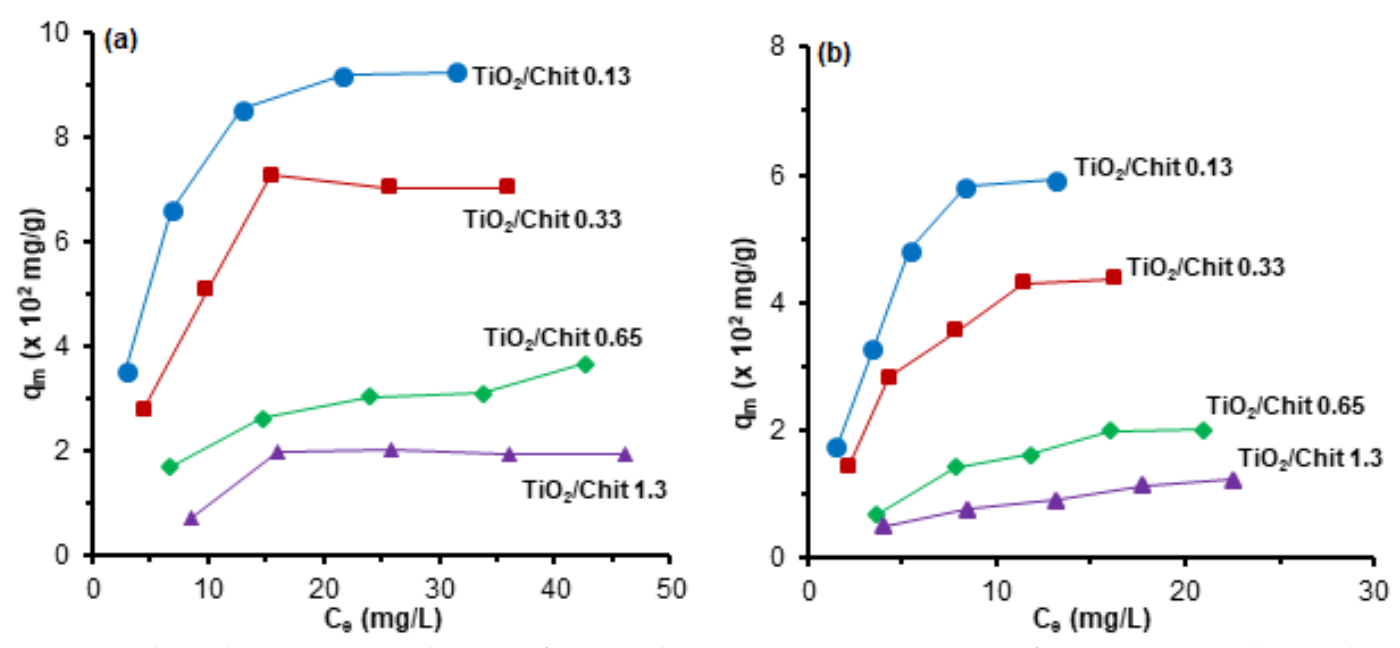

Fig 7. The adsorption isotherm of $\mathrm{TiO}_{2}$-chitosan nanocomposite for $\mathrm{MO}(\mathrm{a})$ and $\mathrm{MB}(\mathrm{b})$

Table 3. The adsorption isotherm constants of $\mathrm{TiO}_{2}$-chitosan nanocomposite for $\mathrm{MO}$ and $\mathrm{MB}$

\begin{tabular}{lllllll}
\hline Nanocomposite & \multicolumn{2}{l}{$\mathrm{q}_{\mathrm{m}}\left(\times 10^{2}(\mathrm{mg} / \mathrm{g})\right)$} & \multicolumn{2}{l}{$\mathrm{K}_{\mathrm{L}}(\mathrm{L} / \mathrm{mg})$} & \multicolumn{2}{c}{$\mathrm{R}^{2}$} \\
\cline { 2 - 7 } Types & $\mathrm{MO}$ & $\mathrm{MB}$ & $\mathrm{MO}$ & $\mathrm{MB}$ & $\mathrm{MO}$ & $\mathrm{MB}$ \\
\hline $\mathrm{TiO}_{2} /$ Chit 0.13 & 6.66 & 6.69 & 0.34 & 0.22 & 0.929 & 0.959 \\
$\mathrm{TiO}_{2} /$ Chit 0.33 & 5.71 & 4.25 & 0.22 & 0.11 & 0.962 & 0.971 \\
$\mathrm{TiO}_{2} /$ Chit 0.65 & 4.34 & 3.33 & 0.13 & 0.11 & 0.982 & 0.946 \\
$\mathrm{TiO}_{2} /$ Chit 1.33 & 2.70 & 1.92 & 0.11 & 0.08 & 0.903 & 0.978 \\
\hline
\end{tabular}

nanocomposite containing the lowest $\mathrm{TiO}_{2}$ had maximum $\mathrm{q}_{\mathrm{m}}$. This result was in accordance with the results of previous studies in which nanocomposite adsorption capacity was not affected by specific surface area but was influenced by the amount of free chitosan in the nanocomposite. The free $\mathrm{OH}$ and $\mathrm{NH}_{2}$ groups in were not bound to $\mathrm{TiO}_{2}$.

\section{The Photodegradation of Cationic and Anionic Dyes Catalyzed by $\mathrm{TiO}_{2}$-Chitosan Nanocomposite}

The photodegradation process was initiated with the adsorption of dyes on the surface of nanocomposites. Under the UV radiation at $340-390 \mathrm{~nm}(3.0-3.65 \mathrm{eV})$, the adsorbed dyes reacted to radical $\mathrm{OH}^{*}$ with $\mathrm{h}^{+}$as an oxidizing agent, or a charge transfer that produces photocatalytic products was occurred [14]. The UV radiation at $340-390 \mathrm{~nm}$ gives out sufficient energy needed by $\mathrm{TiO}_{2}$ photocatalyst to gather photoactive species, which are $\mathrm{e}^{-}(\approx$ electron $)$ and $\mathrm{h}^{+}(\approx$ hole or positively charged species due to the electron lost) on the surface of $\mathrm{TiO}_{2}$ photocatalyst. This phase is called the oxidizing generation phase.

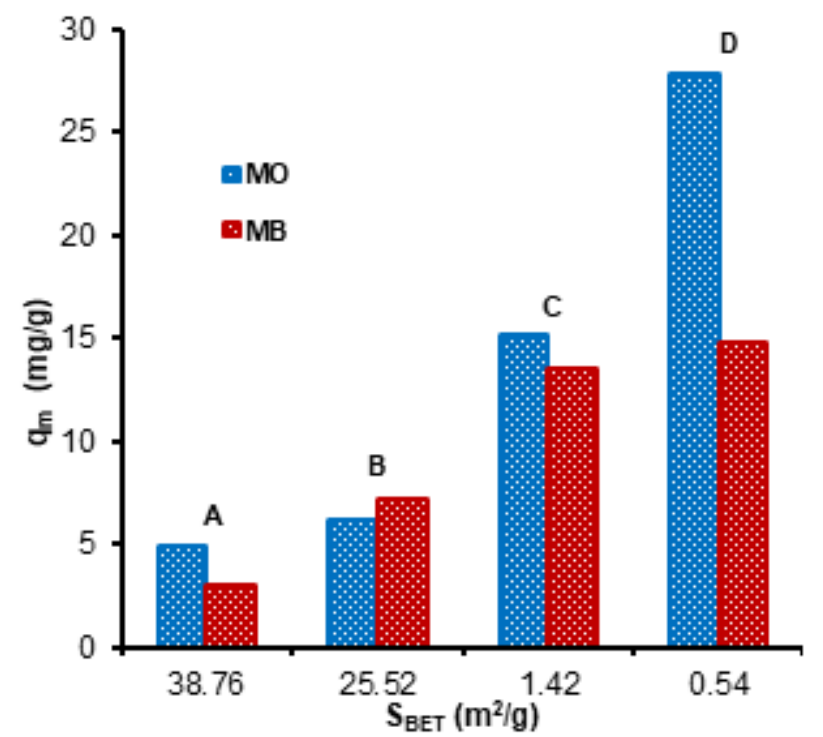

Fig 8. The relationship between specific surface area $\left(\mathrm{S}_{\mathrm{BET}}\right)$ with maximum adsorption capacity $\left(\mathrm{q}_{\mathrm{m}}\right)$ for $\mathrm{MO}$ and $\mathrm{MB}$ (Graph of $\mathrm{A}$ is $\mathrm{TiO}_{2} /$ Chit 1.3 ; $\mathrm{B}$ is $\mathrm{TiO}_{2} /$ Chit 0.65 ; $\mathrm{C}$ is $\mathrm{TiO}_{2} /$ Chit 0.33 , and $\mathrm{D}$ is $\mathrm{TiO}_{2} /$ Chit 0.13)

The mechanism of photodegradation of $\mathrm{MO}$ and $\mathrm{MB}$ by $\mathrm{TiO}_{2}$-nanocomposite chitosan under $\mathrm{UV}$ radiation as illustrated in Fig. 9 (adapted from Nawi 
[15]). The mechanism consists of 3 phases that occur simultaneously. The first phase, the adsorption of anionic dye (MO) on the nanocomposite surface was through electrostatic attraction between sulfoxide $\left(-\mathrm{SO}_{3}{ }^{-}\right)$of $\mathrm{MO}$ molecule and protonated amine $\left(-\mathrm{NH}_{3}{ }^{+}\right)$of chitosan, while the adsorption of cationic dye (MB) occurred through electrostatic attraction between electrons of $\mathrm{MB}$ molecules in aromatic ring and $-\mathrm{NH}_{3}{ }^{+}$group of chitosan. Adsorption of $\mathrm{MB}$ was weaker because of the repulsing force between positive charges from $\mathrm{MB}$ and $-\mathrm{NH}_{3}{ }^{+}$in chitosan [16].

In the second phase, $\mathrm{TiO}_{2}$ which had absorbed UV light could produce holes $\left(\mathrm{h}^{+}\right)$in the valence band $\left(\mathrm{h}^{+}(\mathrm{VB})\right)$ and $\mathrm{e}^{-}$in the conduction band $\left(\mathrm{e}^{-}{ }_{(\mathrm{CB})}\right)$. The reaction on the surface of the $\mathrm{TiO}_{2}$ photocatalyst is:

$\mathrm{TiO}_{2}+\mathrm{h} v \rightarrow \mathrm{TiO}^{*}+\mathrm{h}^{+}{ }_{(\mathrm{VB})}+\mathrm{e}^{-}{ }_{(\mathrm{CB})}$

The $\mathrm{h}^{+}(\mathrm{VB})$ was reacted with aqueous and produced a strong $\mathrm{OH}$ radical:

$\mathrm{h}^{+}{ }_{(\mathrm{VB})}+\mathrm{OH}^{-} \rightarrow \cdot \mathrm{OH}$

$\mathrm{h}^{+}{ }_{(\mathrm{VB})}+\mathrm{H}_{2} \mathrm{O} \rightarrow \cdot \mathrm{OH}+\mathrm{H}^{+}$

Dye molecules adsorbed on the surface of $\mathrm{TiO}_{2}$ nanocomposite could be oxidized:
$\mathrm{MO} / \mathrm{MB}+\mathrm{h}^{+}(\mathrm{VB}) \rightarrow$ oxidation product $^{*}$

$\mathrm{MO} / \mathrm{MB}+\bullet \cdot \mathrm{OH} \rightarrow$ oxidation product $^{*}$

( ${ }^{*} \mathrm{CO}_{2}, \mathrm{H}_{2} \mathrm{O}$ and mineral)

In the third phase, $\mathrm{h}^{+}$on the surface of $\mathrm{TiO}_{2}$ diffuses into the chitosan surface and attacks $\mathrm{MO} / \mathrm{MB}$ molecules on chitosan surface. The MO/MB molecule is positively charged, which could initiate photodegradation reactions, as follows:

$\mathrm{MO}_{\mathrm{ad}} / \mathrm{MB}_{\mathrm{ad}}+\mathrm{h}^{+} \rightarrow \mathrm{MO}_{\mathrm{ad}} \cdot \mathrm{MB}_{\mathrm{ad}} \cdot \mathrm{H}^{+}$

$\mathrm{MO}_{\mathrm{ad}} \cdot / \mathrm{MB}_{\mathrm{ad}}+\mathrm{TiO}_{2} \rightarrow \mathrm{MO}_{\mathrm{ad}}{ }^{+} / \mathrm{MB}_{\mathrm{ad}}{ }^{+}+\mathrm{TiO}_{2}\left(\mathrm{e}^{-}{ }_{(\mathrm{CB})}\right)$

Meanwhile, $\mathrm{e}^{-}{ }_{(\mathrm{CB})}$ had reacted with dissolved oxygen $\left(\mathrm{O}_{2}\right)$ to produce $\mathrm{OH}, \mathrm{O}_{2}{ }^{-}, \mathrm{HO}_{2}$ or $\mathrm{H}_{2} \mathrm{O}_{2}$ radicals. Recombination between $\mathrm{h}^{+}{ }_{(\mathrm{VB})}$ and $\mathrm{e}^{-}{ }_{(\mathrm{CB})}$ was also prevented by this reaction, therefore photodegradation of dyes was increased [17-18].

\section{The effect of $\mathrm{TiO}_{2}$ weight in photodegradation process}

Addition of the amount of $\mathrm{TiO}_{2}$ in $\mathrm{TiO}_{2}$-chitosan nanocomposite could increase the number of $\mathrm{h}^{+}, \mathrm{OH}$ and $\mathrm{e}^{-}$radical, therefore the degradation of $\mathrm{MO}$ and $\mathrm{MB}$ also increased. However, the excess weight of $\mathrm{TiO}_{2}$ could

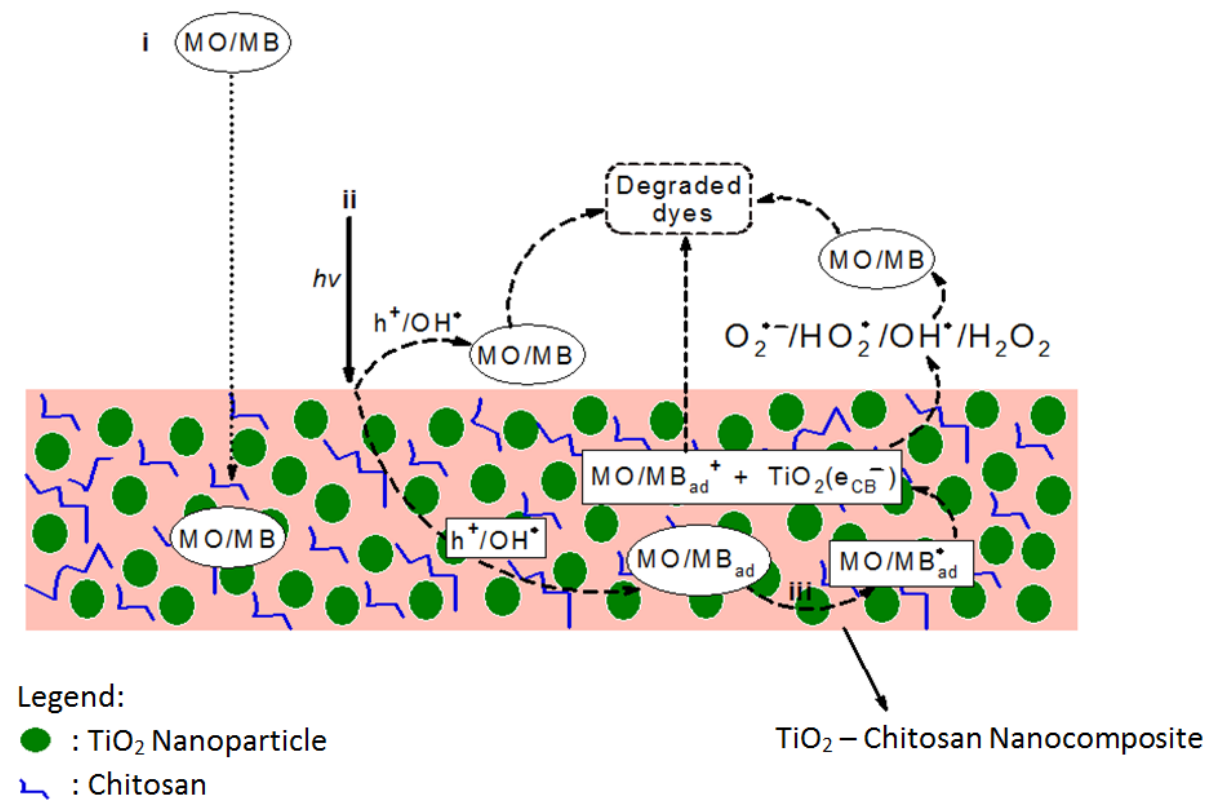

Fig 9. The hypothetical photodegradation mechanisms of $\mathrm{MO}$ and $\mathrm{MB}$ catalyzed by $\mathrm{TiO}_{2}$-chitosan nanocomposite: (i) the adsorption of $\mathrm{MO} / \mathrm{MB}$ on the photocatalyst nanocomposite surface, (II) direct degradation of $\mathrm{MO} / \mathrm{MB}$, which was adsorbed on the surface of the nanocomposite, by $\mathrm{TiO}_{2}$ (III) the oxidation of $\mathrm{MO} / \mathrm{MB}$ which was adsorbed on the chitosan surface, and the charge transfer from $\mathrm{TiO}_{2}$ electron at the conduction band $\left(\mathrm{e}_{\mathrm{cb}}{ }^{-}\right)$ 
reduce photodegradation of dyes (Fig. 10).

$\mathrm{MO}$ and $\mathrm{MB}$ photodegradation occurred until the weight of $\mathrm{TiO}_{2}$ reached a certain amount, around $45 \%$ $\left(\mathrm{TiO}_{2} / \mathrm{Chit}\right.$ 0.65). The excess weight of $\mathrm{TiO}_{2}$ had caused some $\mathrm{TiO}_{2}$ to be outside the chitosan matrix; therefore chitosan could limit the growth of $\mathrm{TiO}_{2}$ particles. $\mathrm{TiO}_{2}$ particles outside the chitosan matrix had a large particle size because they were aggregated. This had caused the light absorbed by $\mathrm{TiO}_{2}$ to be partly because the one exposed to light was the surface of $\mathrm{TiO}_{2}$ only [19].

\section{The kinetics of MO and MB photodegradation}

The kinetic photodegradation of dyes by $\mathrm{TiO}_{2}$ nanoparticles was still a crucial issue. Some researchers reported that the kinetics of the photodegradation reaction followed the Langmuir-Hinshelwood model (L$\mathrm{H}$ model). The validity of the $\mathrm{L}-\mathrm{H}$ model in interpreting photodegradation reactions was easier to understand [2021].

The kinetics of MO and MB Photodegradation was a function of the ratio of the concentration of dyes and time. Measurements were conducted in a solution of 20 $\mathrm{mg} / \mathrm{L} \mathrm{MO}$ and $10 \mathrm{mg} / \mathrm{L} \mathrm{MB}$. The effect of the ratio of initial concentration $(\mathrm{Co})$ and concentration after $\mathrm{t}(\mathrm{min})$ (Ce) during photodegradation was shown in Fig. 11.

Fig. 11 showed that the photodegradation rate of $\mathrm{MO}$ and MB followed the first order (pseudo) reaction.

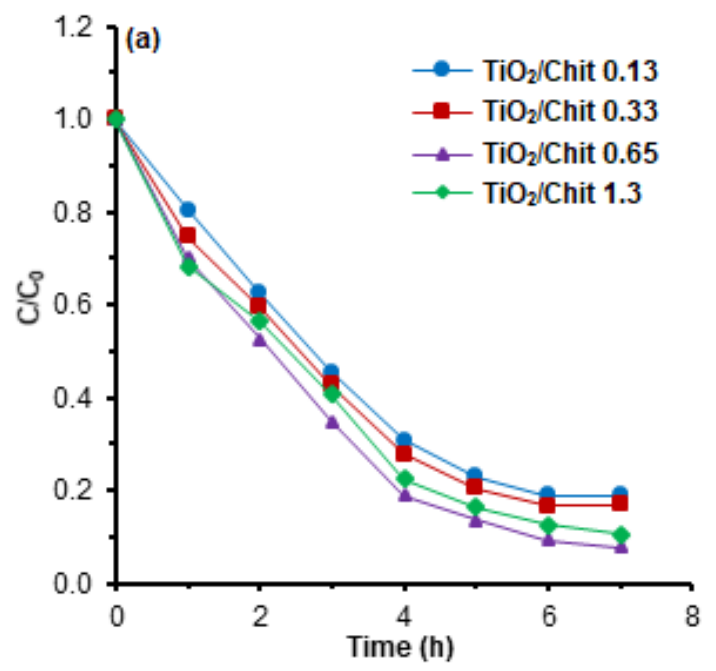

Fig 11. (a) Langmuir-Hinshelwood kinetic of MO photodegradation (b) Langmuir-Hinshelwood kinetic of MB photodegradation
This was because the reaction rate depended on the reactants concentration at low dye concentrations. The kinetic constant $(\mathrm{k})$ is determined by the LangmuirHinshelwood (L-H) equation, as follows [22]:

$\mathrm{r}=-\frac{\mathrm{dC}}{\mathrm{dt}}=\frac{\mathrm{kK}_{\mathrm{L}} \mathrm{C}_{\mathrm{e}}}{1+\mathrm{K}_{\mathrm{L}} \mathrm{C}_{\mathrm{e}}}=\ln \left(\frac{\mathrm{C}_{0}}{\mathrm{C}_{\mathrm{e}}}\right)+\mathrm{K}_{\mathrm{L}}\left(\mathrm{C}_{0}-\mathrm{C}_{\mathrm{e}}\right)=\mathrm{kK}_{\mathrm{L}} \mathrm{t}$

$r$ is the reaction rate, $C_{0}$ is the initial concentration, Ce is the concentration after $t$, with $t$ represent the reaction time ( $\mathrm{min}), \mathrm{K}_{\mathrm{L}}$ is the Langmuir adsorption constant, and

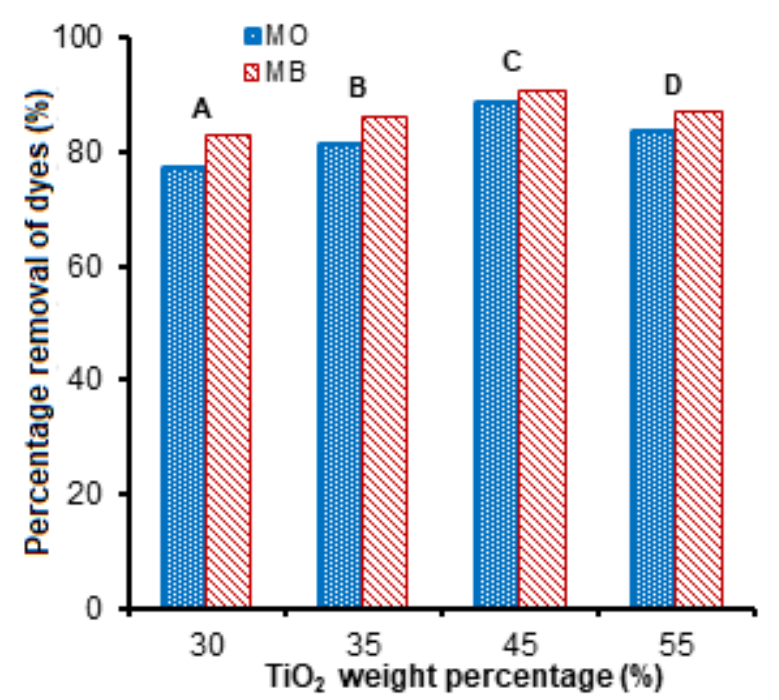

Fig 10. The effect of $\mathrm{TiO}_{2}$ weight in nanocomposite to dye removal (Graph of $\mathrm{A}$ is $\mathrm{TiO}_{2} /$ Chit 0.13 ; $\mathrm{B}$ is $\mathrm{TiO}_{2} /$ Chit 0.33 ; $\mathrm{C}$ is $\mathrm{TiO}_{2} /$ Chit 0.65 ; and $\mathrm{D}$ is $\mathrm{TiO}_{2} /$ Chit 1.3 )

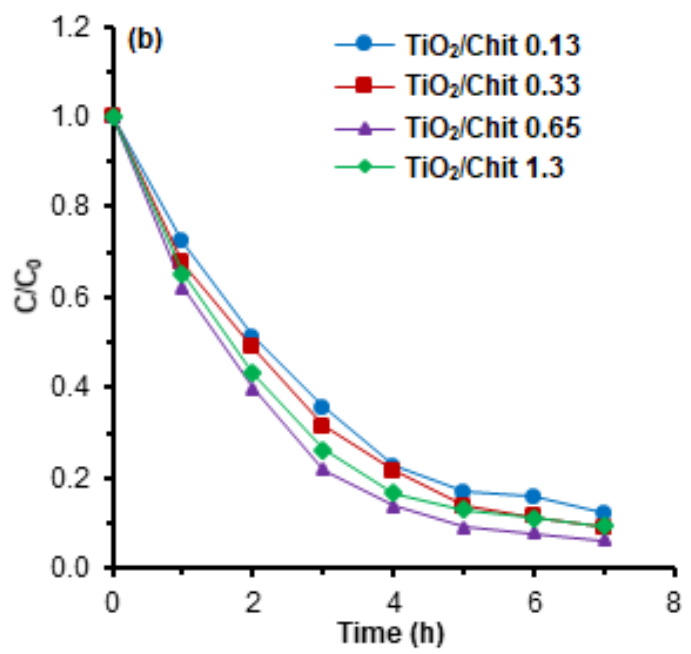


$\mathrm{k}$ is the kinetic constant $\left(\mathrm{min}^{-1}\right)$. If $\mathrm{K}_{\mathrm{L}} \mathrm{C}_{\mathrm{e}}<<$; then $\mathrm{r}=\mathrm{kK}_{\mathrm{L}} \mathrm{C}_{\mathrm{e}}$ with the limits of integration are $\mathrm{C}_{\mathrm{e}}=\mathrm{C}_{0}$ at $\mathrm{t}=0$ and $\mathrm{C}_{\mathrm{e}}=$ $\mathrm{C}_{e}$ at $\mathrm{t}=\mathrm{t}$. Then, the equation of $\mathrm{L}-\mathrm{H}$ can be simplified into the first order reaction, as follows:

$-\ln \frac{\mathrm{C}_{\mathrm{e}}}{\mathrm{C}_{0}}=\mathrm{k}_{\mathrm{Obs}} \mathrm{t}$

$\mathrm{k}_{\mathrm{Obs}}$ was the observed kinetic constant $\left(\mathrm{min}^{-1}\right)$ and $\mathrm{k}_{\mathrm{Obs}}=$ $\mathrm{kK}_{\mathrm{L}}$. The kinetic parameter of $\mathrm{k}_{\mathrm{Obs}}$ was determined by fitting the curve of $-\ln \mathrm{C}_{\mathrm{e}} / \mathrm{C}_{0}$ vs $\mathrm{t}$, and the observed kinetic constant was determined based on the slope value of the graph regression equation. The graph describing the observed kinetic constant $\left(\mathrm{k}_{\mathrm{obs}}\right)$ in the photodegradation of $\mathrm{MO}$ and $\mathrm{MB}$ were given in Fig. 12.

Fig. 12 showed that photodegradation of $\mathrm{MO}$ and MB followed a (pseudo) first-order reaction. The (pseudo) first-order reaction is a rate reaction depends linearly on the concentration of the dyes. When adsorption was one of the kinetic determinant parameters, the kinetic constant $(\mathrm{k})$ that had been affected by the adsorption process was determined by the $\mathrm{k}_{\mathrm{Obs}}=$ $k . K_{L}$ equation. The parameters of the observed kinetic constant rate $\left(\mathrm{k}_{\mathrm{obs}}\right)$ did not consider the adsorption during heterogeneous photocatalytic reactions. The $\mathrm{K}$ value was given in Table 4 .

Table 4 showed that the highest observed kinetic $\left(\mathrm{k}_{\mathrm{Obs}}\right)$ was achieved by $\mathrm{TiO}_{2} / \mathrm{Chit} 0.65$, while the highest corrected kinetic $(\mathrm{k})$ was achieved by $\mathrm{TiO}_{2} / \mathrm{Chit}$ 1.3. The $\mathrm{TiO}_{2} /$ Chit 0.65 nanocomposite had the highest observed kinetic ( $\mathrm{k}_{\text {obs }}$ ) because it has the highest $\mathrm{E}_{\mathrm{g}}$ value and the highest crystallinity [19]. On the other hand, the $\mathrm{TiO}_{2} /$ Chit 1.3 nanocomposite had the highest corrected kinetic $(\mathrm{k})$ because the adsorption equilibrium constant $\left(\mathrm{k}_{\mathrm{L}}\right)$ value of $\mathrm{TiO}_{2} /$ Chit 1.3 was the lowest, hence the time needed by dyes to achieve the adsorption equilibrium on the $\mathrm{TiO}_{2} / \mathrm{Chit} 1.3$ nanocomposite was shorter. The relationship between $\mathrm{TiO}_{2}$ weight in nanocomposite and observed kinetic $\left(\mathrm{k}_{\mathrm{Obs}}\right)$ in $\mathrm{MO}$ and $\mathrm{MB}$ photodegradation is given in Fig. 13.

Fig. 13 indicated that the increasing weight of $\mathrm{TiO}_{2}$ in the nanocomposite enhances the photodegradation rate. The excess $\mathrm{TiO}_{2}$ content in nanocomposite produced more $\mathrm{OH}$ radicals. It was beneficial to improve
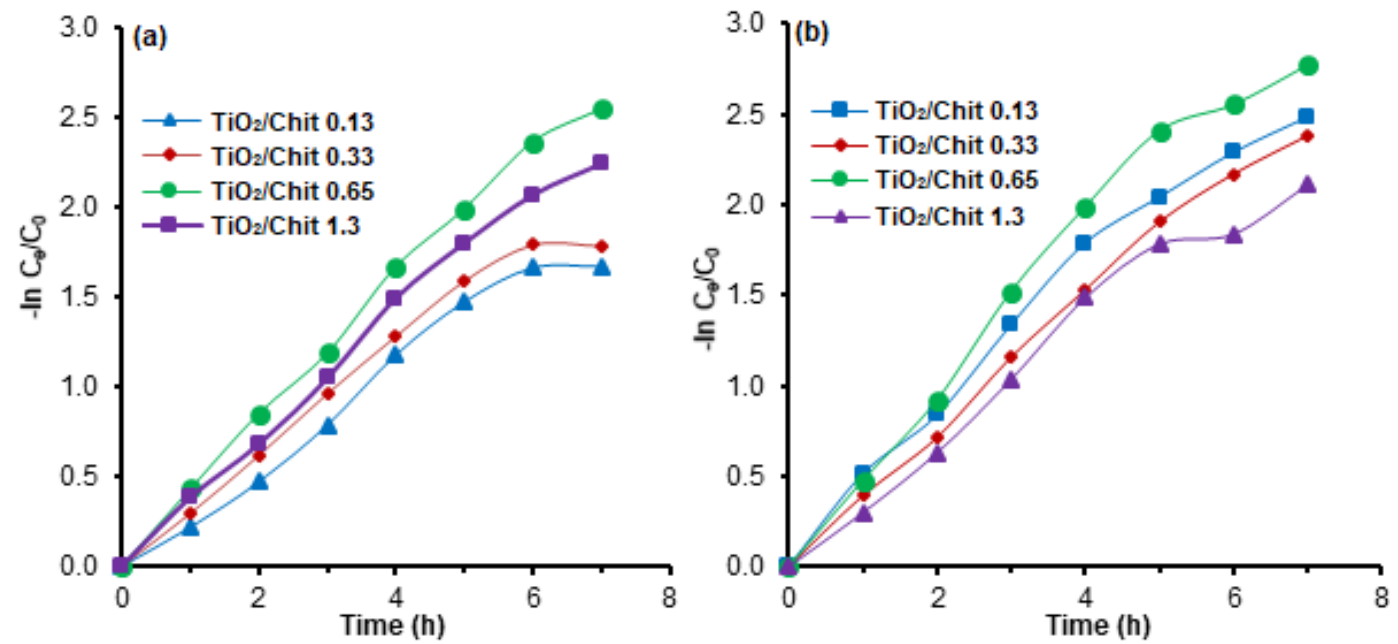

Fig 12. (a) Observed kinetic constant $\left(\mathrm{k}_{\mathrm{Obs}}\right)$ of MO photodegradation follows the first order reaction (b) Observed kinetic constant $\left(\mathrm{k}_{\mathrm{Obs}}\right)$ of $\mathrm{MB}$ photodegradation follows the first order reaction

Table 4. The photodegradation rate parameters of $\mathrm{MO}$ and $\mathrm{MB}$ catalyzed by $\mathrm{TiO}_{2}$-chitosan nanocomposite

\begin{tabular}{lcccccc}
\hline \multirow{2}{*}{$\begin{array}{l}\text { Nanocomposite } \\
\text { Types }\end{array}$} & \multicolumn{2}{c}{$\mathrm{k}_{\text {obs }}\left(\mathrm{min}^{-1}\right)$} & \multicolumn{2}{c}{$\mathrm{K}_{\mathrm{L}}(\mathrm{L} / \mathrm{Mg})$} & \multicolumn{2}{c}{$\mathrm{k}\left(\mathrm{x} 10^{2}(\mathrm{~min})\right)$} \\
\cline { 2 - 7 } & $\mathrm{MO}$ & $\mathrm{MB}$ & $\mathrm{MO}$ & $\mathrm{MB}$ & $\mathrm{MO}$ & $\mathrm{MB}$ \\
\hline $\mathrm{TiO}_{2} /$ Chit 0.13 & 100.5 & 97.13 & 0.034 & 0.028 & 2.951 & 3.396 \\
$\mathrm{TiO}_{2} /$ Chit 0.33 & 104.6 & 103.5 & 0.022 & 0.016 & 4.670 & 6.347 \\
$\mathrm{TiO}_{2} /$ Chit 0.65 & 146.9 & 158.4 & 0.013 & 0.011 & 10.57 & 13.89 \\
$\mathrm{TiO}_{2} /$ Chit 1.3 & 130.5 & 144.2 & 0.011 & 0.008 & 11.64 & 16.58 \\
\hline
\end{tabular}

Imelda Fajriati et al. 


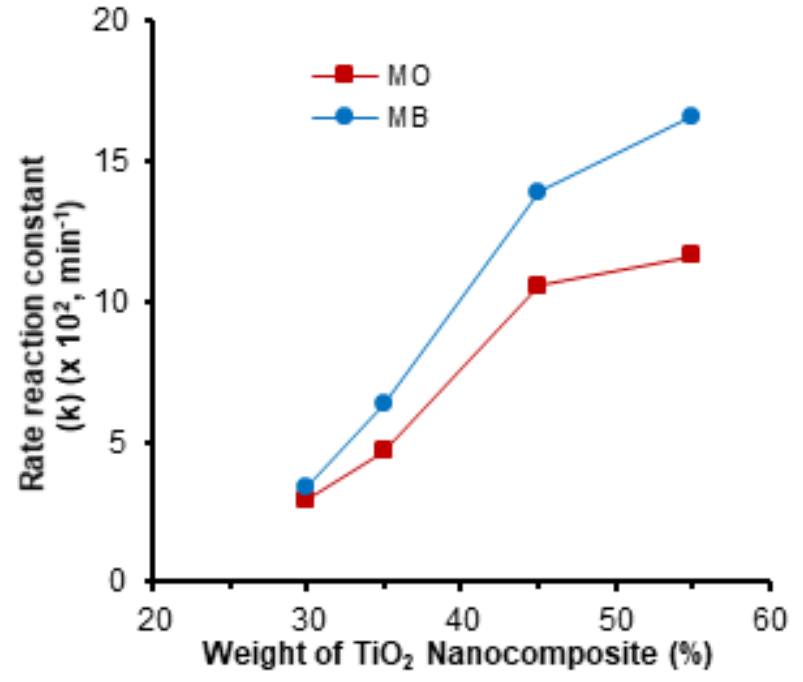

Fig 13. The relationship between $\mathrm{TiO}_{2}$ weight with the kinetics $(\mathrm{k})$ of $\mathrm{MO}$ and $\mathrm{MB}$ photodegradation

nanocomposites performance as a photocatalyst, because much more $\mathrm{OH}$ radicals had been able to increase photodegradation reactions.

The different kinetics in various levels of $\mathrm{TiO}_{2}$ (Fig. 11) indicated different activation energy between nanocomposites. The energy activation affected the rate reaction. When the catalytic reaction occurred in constant temperature, thus the kinetic was only influenced by the activation energy $\left(\mathrm{E}_{\mathrm{a}}\right)$ [22].

Two determining factors for the activation energy in nanocomposite were the weight of $\mathrm{TiO}_{2}$ and the distribution of $\mathrm{TiO}_{2}$ in the nanocomposite. Based on different energy activations in the nanocomposite, it was predicted that the distribution of $\mathrm{TiO}_{2}$ in nanocomposite followed two types. First, $\mathrm{TiO}_{2}$ was distributed closed in the chitosan matrix space. Second, $\mathrm{TiO}_{2}$ was distributed inside and outside the chitosan matrix.

The first type occurred in the nanocomposites containing low $\mathrm{TiO}_{2}$ weights, (as $\mathrm{TiO}_{2} /$ Chit 0.13 and $\mathrm{TiO}_{2} /$ Chit 0.33), while the second type occurred in the nanocomposite containing high $\mathrm{TiO}_{2}$, (as in $\mathrm{TiO}_{2} /$ Chit 0.65 and $\mathrm{TiO}_{2} /$ Chit 1.3). The distribution of $\mathrm{TiO}_{2}$ inside and outside the chitosan matrix had a higher photodegradation than when $\mathrm{TiO}_{2}$ was in the chitosan matrix. This result was confirmed by the increase in photodegradation reaction kinetic.

\section{- CONCLUSION}

$\mathrm{TiO}_{2}$-chitosan nanocomposite was a photocatalyst that could remove cation $(\mathrm{MB})$ and anion $(\mathrm{MO})$ dyes by adsorption and photodegradation processes. Photodegradation of $\mathrm{MO}$ was greater than MB. MO was also more easily absorbed by nanocomposite than $\mathrm{MB}$ because MO had electrostatic attraction as a driving force. The adsorption process was dominant when the weight of $\mathrm{TiO}_{2}$ in nanocomposite was low due to higher amounts of $-\mathrm{OH}$ and $-\mathrm{NH}_{2}$ in the chitosan matrix. The photodegradation kinetics of $\mathrm{MO}$ and $\mathrm{MB}$ followed a first-order reaction. The highest kinetic constant $(\mathrm{k})$ is obtained by the largest $\mathrm{TiO}_{2}$ nanocomposite.

\section{- ACKNOWLEDGMENTS}

The authors would like to thank the Lembaga Pengelola Dana Pendidikan (LPDP), the Ministry of Finance of the Republic of Indonesia for the research funding, contract numbers, No. PRJ-363/LPDP/2013.

\section{- REFERENCES}

[1] Dawood, S., and Sen, K.T., 2014, Review on dye removal from its aqueous solution into alternative cost effective and non-conventional adsorbents, $J$. Chem. Proc. Eng., 1, 1-7.

[2] Reddy, D.H.K., and Lee, S.M., 2012, Water pollution and treatment technologies, J. Environ. Anal. Toxicol., 2 (5), 1000e103.

[3] Fajriati, I., Mudasir, and Wahyuni, E.T., 2013, Room-temperature synthesis of $\mathrm{TiO}_{2}$-Chitosan nanocomposites photocatalyst, Proceeding of The $3^{\text {rd }}$ Annual Basic Science International Conference, Faculty Mathematics and Natural Sciences, University of Brawijaya, C10-1-C10-5.

[4] Fajriati, I., Mudasir, and Wahyuni, E.T., 2014, Photocatalytic decolorization study of methyl orange by $\mathrm{TiO}_{2}$-chitosan nanocomposites, Indones. J. Chem., 14 (3), 209-218.

[5] Mills. A., and Wang, J., 1999, Photobleaching of methylene blue sensitized by $\mathrm{TiO}_{2}$ : An ambiguous system?, J. Photochem. Photobiol., A, 127 (1-3), 123-134. 
[6] Bazrafshan, E., Zarei, A.A., Nadi, H., and Zazouli, M.A., 2014, Adsorptive removal of Methyl Orange and Reactive Red 198 dyes by Moringa peregrina ash, Indian J. Chem. Technol., 21, 105-113.

[7] Nawi, M.A., Jawad, A.H., Sabar, S., and Ngah, W.S.W., 2011, Photocatalytic-oxidation of solid state chitosan by immobilized bilayer assembly of $\mathrm{TiO}_{2-}$ chitosan under a compact household fluorescent lamp irradiation, Carbohydr. Polym., 83 (3), 1146-1152.

[8] Kablan, T., Clément, Y.Y., Françoise, K.A., and Mathias, O.K., 2008, Determination and modeling of sorption isotherms of chitosan and chitin, Acta Chim. Slov., 55, 677-682.

[9] Allen, T., 1997, Particle Size Measurement. Volume 2: Surface Area and Pore Size Determination, $5^{\text {th }}$ ed., Springer, Netherlands.

[10] Sayilkan, F., and Emre, F.B., 2016, Characterization and photocatalytic properties of $\mathrm{TiO}_{2} /$ chitosan nanocomposites synthesized by a hydrothermal process, Turk. J. Chem., 40, 28-37.

[11] Rouquerol, F., Rouquerol, J., and Sing, K., 1999, "Assessment of Mesoporosity" in Adsorption by Powders and Porous Solids, Elsevier, 191-217.

[12] Annadurai, G., Ling, L.Y., and Lee, J.F., 2008, Adsorption of reactive dye from an aqueous solution by chitosan: Isotherm, kinetic, and thermodynamic analysis, J. Hazard. Mater., 152 (1), 337-346.

[13] Ling, S.L.Y., Yee, C.Y., and Eng, H.S., 2011, Removal of a cationic dye using deacetylated chitin (chitosan), J. Appl. Sci., 11 (8), 1445-1448.

[14] Hoffmann, M.R., Martin, S.T., Choi, W., and Bahnemann, D.W., 1995, Environmental application of semiconductor photocatalysis, Chem. Rev., 95 (1), 69-96.

[15] Nawi, M.A., and Sheilatina, S., 2012, Photocatalytic decolorization of Reactive Red 4 dye by an immobilized $\mathrm{TiO}_{2} /$ chitosan layer by layer system, $J$. Colloid Interface Sci., 372 (1), 80-87.

[16] Zubieta, C.E., Messina P.V., Luengo C., Dennehy, M., Pieroni, O., and Schulz, P.C., 2008, Reactive dyes remotion by porous $\mathrm{TiO}_{2}$-chitosan material, $J$. Hazard. Mater., 152 (2), 765-777.

[17] Mohammadi, A., and Karimi, A.A., 2017, Methylene blue removal using surface-modified $\mathrm{TiO}_{2}$ nanoparticles: a comparative study on adsorption and photocatalytic degradation, $J$. Water Environ. Nanotechnol., 2 (2), 118-128.

[18] Trandafilović, L.V., Jovanović, D.J., Zhang, X., Ptasińska, S., and Dramićanin, M.D., 2017, Enhanced photocatalytic degradation of methylene blue and methyl orange by $\mathrm{ZnO}: \mathrm{Eu}$ nanoparticles, Appl. Catal., B, 203, 740-752.

[19] Fajriati, I., Mudasir, and Wahyuni, E.T., 2017, The effect of $\mathrm{pH}$ and aging time on the synthesis of $\mathrm{TiO}_{2}$-chitosan nanocomposites as photocatalyst using sol-gel method at room temperature, Molekul, 12 (2), 117-125.

[20] Lazar, M.A., Varghese, S., and Nair, S.S., 2012, Photocatalytic water treatment by titanium dioxide: Recent updates, Catalysts, 2 (4), 572-601.

[21] Hamad, H.A., Sadik, W.A., Ab El-Latif, M.M., Kashyout, A.B., and Fateha, M.Y., 2016, Photocatalytic parameters and kinetic study for degradation of dichlorophenol-indophenol (DCPIP) dye using highly active mesoporous $\mathrm{TiO}_{2}$ nanoparticles, J. Environ. Sci., 43, 26-39.

[22] Salehi, M., Hashemipour, H., and Mirzaee, M., 2012, Experimental study of influencing factors and kinetics in catalytic removal of methylene blue with $\mathrm{TiO}_{2}$ nanopowder, Am. J. Environ. Eng., 2 (1), 1-7. 